\title{
Reflexões sobre o ato de burlar sob o olhar da TAR
}

\section{Reflections on the act of cheating under the perspective of ANT}

\author{
Reflexiones sobre elacto de engaño bajo la perspectiva de la \\ ANT
}

\section{Lauro Rodriguez de Pontes*}

Universidade do Estado do Rio de Janeiro - UERJ, Rio de Janeiro, Rio de Janeiro, Brasil

\begin{abstract}
RESUMO
Este artigo visa discorrer sobre o ato de burlar no campo da tecnologia da informação usando a teoria ator rede (TAR) como referencial teórico; entendendo Burlar como um agente múltiplo e sempre presente como possibilidade em qualquer evento. A burla também surge da impossibilidade de se antever o que as interações sociotécnicas podem produzir.

A burla dentro de tecnologia da informação e comunicação (TIC) será tomada como caminho a ser construído no processo de investigação. Os princípios da TAR aqui definidos como "conceitos-luva" serão utilizados como base argumentativa e teórica.
\end{abstract}

Palavras-chave: tecnologia, Informação, subjetividade, redes, sociedade.

\begin{abstract}
This article aims to discuss the act of cheating using the actor network theory (ANT) as a theoretical framework. Understanding cheating as a multiple agent and always present as a possibility in any event, the cheat within the information and communication technology (ICT) will be taken as the path to be built throughout the research process.

This article aims to discuss the act of cheating in the field of information technology using actor network theory (ART) as a theoretical framework. Circumventing understood as a multi agent and ever present as a possibility in any event. The fraud also arises from the impossibility of foreseeing what sociotechnical interactions can produce.

The fraud within the information and communication technology (ICT) will be taken as the path to be built into the research process. The principles of TAR defined here as "concepts-glove" will be used as theoretical basis and argumentative.
\end{abstract}

Keywords: technology, information, subjectivity, networks, society.

\section{RESUMEN}

Este artículo tiene como objetivo discutir el acto de hacer trampa en el campo de la tecnología de la información utilizando la teoría actor-red (TAR) como marco teórico. Eludiendo entendida como un agente de múltiples y siempre presente como una posibilidad en cualquier caso. El fraude también 
se debe a la imposibilidad de prever lo que las interacciones socio-técnicos pueden producir.

El fraude en la información y la comunicación (TIC) se tomará como la ruta de acceso que se construirá en el proceso de investigación. Los principios de la TAR definidas aquí como "conceptos-guante" se utilizarán como base teórica y argumentativa.

Palabras clave: tecnología, información, subjetividad, redes, sociedad.

\section{Na batida da TI C, referenciando a TAR}

A Teoria Ator-Rede (TAR) nasceu pelo desenvolvimento de um grupo multidisciplinar (antropólogos, sociólogos e engenheiros franceses e ingleses associados), dentre os quais Bruno Latour, Michel Callon e J ohn Law. Embora muitas vezes a Teoria Ator-Rede seja considerada uma metodologia, "ela na prática alcançou o estatuto de uma teoria, quer pelas ambições do seu método (abolição do pensamento dualístico) quer pela sua reconceitualização sistemática de práticas de pesquisa, que envolvem uma nomenclatura extensa e original". (Wilkinson, 2004). A TAR consiste em "seguir as coisas através das redes em que elas se transportam e descrevê-las em seus enredos" (Latour, 2004). "Ator é tudo que movimenta, deixa traço, produz efeito, referindo-se a pessoas, lugares, coisas, animais, objetos, máquinas, etc., tudo que é humano e não-humano" (Latour, 2001). Cada ator possui seus papéis diversos e distintos criando nós nessa rede totalmente interconectada. Assim ocorrem pequenas conexões em pequenos grupos como em cada núcleo familiar ou de trabalho e grandes conexões muito mais complexas (bairros, vizinhança e sociedades em geral).

"Valendo-se da denominação de actante para designar tanto humanos quanto não humanos, a TAR objetiva abandonar a ideia de substância para destacar a ideia de agência, ação. Com isso, coloca-se em foco o fato de que os actantes acontecem na medida em que habitam o mundo, que se vinculam aos demais elementos desse mundo. Ou ainda, eles são mais autônomos quanto mais conectados estão. Em outras palavras, quanto mais vínculos se estabelecem, mais sua existência pode ser vista no mundo, e, assim, pode ser acompanhada em seus efeitos por aquele que quer investigá-los." (Tsallis, 2009, pag, 146).

O conceito de sociedade está intimamente ligado a essa noção de redes humanas. O estabelecimento dela leva ao desenvolvimento da relação presente entre o homem e o meio. Redes de distribuição de serviços básicos, por exemplo, possuem as mesmas características de inter-relação e co-dependência que a informatização na atualidade, 
representada pela internet, que é a grande actante da tecnologia da informação.

Sempre sob a ótica da TAR ou ANT, que em inglês tem sua sinonímia com "ant" (formiga), faz lembrar que ela explora o ambiente numa postura comparável ao pesquisador não moderno (Latour, 2006). Para a formiga e para internet, a informação também não é linear. Esta se dá através de desvios, de caminhos curvos, pequenos atalhos que abrem para outros tantos caminhos e assim sucessivamente. Um fim pode sempre ser modificado em função de desvios, através de mediações imprevisíveis. Assim o termo coletivo torna-se mais adequado que o de sociedade, pois inclui uma combinação heterogênea de humanos e não-humanos, nunca concebidos em si, só adquirindo sentido quando articulados, vinculados em função do coletivo em que estão inseridos. Neste coletivo, um ator não age simplesmente, mas é levado a agir. Ele é superado por sua ação. Em outros termos, ele não apenas faz, a rede o faz fazer, afeta e é afetado pelas proposições articuladas que circulam na rede.

\section{Conceitos-luva}

A partir de uma expressão lingüística comum - "cair como uma luva" - são nominados como conceitos-luva os conceitos-chave da teoria ator-rede que embasam teoricamente a burla como forma e prática. Eles encaixam perfeitamente ao argumento central e foram escolhidos e tecidos sobre conceitos iniciais da TAR, referendando as ideias e movimentos que acabam por produzir o ato de burlar. Assim, serão tratados assuntos sobre os quais versa a teoria ator-rede em relação ao objeto do presente Artigo. A TAR é a lupa ou a luneta, dependendo da necessidade de aproximação, pela qual a burla será metodologicamente observada e pensada como conseqüência da concatenação desses conceitos.

\section{As construções dos fatos}

No capitulo 3 do livro ciência em ação, Latour resume princípios metodológicos apresentados. O primeiro fala em desistir de discurso ou opinião sobre ciência feita e em lugar disso seguir os cientistas em ação. Para acompanhar a desarrumação que a burla provoca no modo oficial de se produzir tecnologia da informação, é necessário desistir antecipadamente da fala, da forma, do jeito oficial estabelecido. Nenhum conceito técnico deve ser tomado como verdadeiro, sem acompanhar sua condução e construção histórica. E a história da tecnologia da informação mostra que não há afirmação definitiva sobre como algo é, do ponto de vista da produção de equipamentos 
ou softwares e sim como tudo sofre processos de adaptação e conduta sobre os usuários dos mesmos.

A realidade tem muitos matizes, como a objetividade, e depende de um número de elementos amarrados à alegação feita (Latour, 2000). Há muitos elementos além dos oficiais amarrados ao lançamento de qualquer produto de tecnologia da informação. Pego como exemplo o lançamentos de sistemas operacionais de computadores, Os famosos Windows, que desde suas primeiras versões vêm tentando proibir sua cópia não autorizada, produzindo dispositivos de controle (senhas, números de série, autenticações on-line). Porém horas depois do seu lançamento, um conjunto de outros programas, criados por programadores independentes, "quebram" essas barreiras e passam a permitir o uso pleno das suas funções.

Um campo nebuloso de possibilidades se faz no entendimento os caminhos percorridos. Parece que a motivação dos crackers é a resistência ideológica em virtude dos preços abusivos praticados ou talvez pelo "título" de ser quem primeiro conseguiu burlar a proteção. Porém nenhum sistema é caixa-preta. Por serem códigos escritos em milhões de linhas de programação, essas sempre podem ser modificadas.

\section{Tradução ou translação}

O conceito-luva feito sob medida para esse artigo é o de tradução. "Traduzir (ou transladar) significa deslocar objetivos, interesses, dispositivos, seres humanos. Implica desvio de rota, invenção de um elo que antes não existia e que de alguma maneira modifica os elementos imbricados. As cadeias de tradução referem-se ao trabalho pelo qual os atores modificam, deslocam e transladam os seus vários e contraditórios interesses" (Freire, 2006).

"Transladar interesses significa, ao mesmo tempo, oferecer novas interpretações desses interesses e canalizar as pessoas para direções diferentes" (op. cit. 194).

A burla produz desvios na conduta prática oficial. Ela incita novas interações tanto entre atores e desses com os dispositivos alterados ou adaptados para obter os efeitos que o método oficial produz. A tradução é prática dos dois processos.

A Burla muitas vezes seduz. No conceito de translação numero três (se você desviasse só um pouquinho), Latour fala do aspecto irresistível da estratégia (que se traduz em argumento fundamental) da burla. Citando o conselho descrito por ele como o que a serpente deu a Eva: "Você pode atingir seu objetivo indo em frente, mas se trilhar meu caminho vai chegar até ele mais depressa, seria um atalho". Burlar significa essencialmente isso: não se trata de mudar o objetivo, afastando do mesmo. Simplesmente se produz um atalho, 
outra maneira de se atingir o mesmo resultado. Para isso acontecer a contento Latour completa, afirmando a necessidade de três condições: o caminho principal está bloqueado (no caso o método oficial não é a melhor escolha, seja lá por que razão); o novo desvio está bem sinalizado (produzir a burla é algo possível e o resultado é o esperado); o desvio parece pequeno (depois de produzida, a burla é replicada de forma muito fácil).

\section{A recalcitrância}

Olhar a burla como posição de resistência ao método oficial imposto, como reação aos produtos caixas-pretas entregues pelos fabricantes encontra dentro da teoria ator-rede um conceito bem interessante: a recalcitrância. Recalcitrar é relacionar-se resistindo. A recalcitrância aparece no momento em que o encontro se dá, porém não se produz relação dicotômica nesse encontro, pois as situações se estabilizam em um novo cenário, reconfigurando-se na situação especifica.

A burla recalcitra, faz com que a metodologia convencional tenha que se adaptar à realidade que contém a burla como parte integrante. Novos desdobramentos e vínculos se dão em função da tentativa do método oficial de parar a burla. Produzindo assim, produtos, bloqueios, sistemas de controle e segurança. Outro ponto que destacaria na recalcitrância é como ela torna possível perceber a singularidade, uma vez que ela redefine os vínculos, redesenha as bordas do cenário e até mesmo estabelece novos cenários. Em suma, a recalcitrância é essa trava a um fluxo ininterrupto do cotidiano.

Os atores se definem antes de tudo como obstáculos, escândalos, como aquilo que suspende a superioridade, que incomoda a dominação, que interrompe o fechamento e a composição do coletivo. Para falar de maneira popular, os atores humanos e não-humanos aparecem, então, como importunos. É pela noção de recalcitrância que convém de modo especial, definir sua ação. (Latour, 2004, p. 150)

A definição do parágrafo acima é amplamente usada em trabalhos acadêmicos dentro da explicação sobre recalcitrância. A razão é que ela define muito bem o conceito, por mostrar que todo movimento, relação ou acontecimento é sempre único e está atrelado aos atores que compõem o cenário do instantâneo do momento acontecido. Que vai mostrando a performance sociotécnica em "tempo real". Parafraseando metaforicamente o próprio Latour (o "faz fazer"): os acontecimentos acontecem.

\section{A caixa-preta}


(Harman, 2009) define o conceito de caixa preta como qualquer actante tão firmemente estabelecido que nós podemos desconsiderar seu interior ("We are able to take its interior for granted"). As propriedades internas de uma caixa preta não contam, na medida em que estivermos preocupados somente com seu input e output.

O conceito de caixa-preta de Latour se aplica perfeitamente ao modus operandi da tecnologia da informação oficial. Produtos e serviços são desenvolvidos, formatados e oferecidos para o público em geral que interage com a "coisa pronta" sem questionar. Burlar significa abrir a caixa de pandora (Latour, 2001) e não só entender o seu conteúdo, mas também modificá-lo para que de outra forma, se possa obter o mesmo resultado.

O método oficial produz caixas pretas, cujo objetivo é produzir apenas interação entre o usuário e o resultado que o dispositivo irá produzir. Toda e qualquer discussão sobre a caixa preta se torna desnecessária, apenas o conhecimento de suas entradas e saídas deve ser levado em consideração.

Uma caixa-preta é quando um fato ou um artefato é dado como pronto, adquirindo uma estabilidade provisória na medida em que cessam as controvérsias em torno dela. Diz-se então que fechamos a caixa e ela assim permanecerá enquanto fato e artefato funcionarem bem. Se alguma coisa deixa de funcionar ou se algo ou alguém ficou excluído, voltamos às controvérsias e reabrimos a caixa (Latour, 2000).

\section{Ser moderno é coisa do passado}

Em seu livro "Jamais fomos modernos", Latour (1994) critica a impressão (moderna) de viver um tempo novo que rompe com o passado. Isso acontece quando se faz a conexão entre a enorme quantidade de eventos que compõem o cotidiano. É a substituição de seus elementos por outros que se tornarão igualmente coerentes no período seguinte, que nos dá a impressão que o tempo passa: um fluxo contínuo indo do futuro ao passado. É preciso haver o movimento de substituição das coisas por outras melhor alinhadas, assim o tempo se torna um fluxo. A temporalidade moderna é duas vezes assimétrica, porque assinala uma ruptura na passagem regular do tempo e assinala um combate no qual há vencedores e vencidos. (Latour, 1994).

A realidade é sempre tomada por irrupções de actantes na história dos modernos. Conceitos, descobertas, invenções, tudo passa a receber a distinção entre o tempo "antes" e o "depois". A cada vez, será calculado o tempo a partir destes começos miraculosos. Essa necessidade de temporalizar e separar incorre no erro da não percepção do contínuo. Numa falsa sensação de esclarecimento, a 
temporalidade moderna promete sair do caos reinante anterior e da confusão entre as coisas e os homens, para um futuro que não confundirá mais. O presente é traçado por quebras, propostas como revolucionárias e direcionadas para cima (o progresso) e para baixo (a decadência), por onde se multiplicam as projeções dos actantes. Como não se pode definir origens das entidades naturais e sociais, 0 pensamento moderno cria a noção de progresso ou decadência proveniente de uma classificação dos actantes cujo crescimento não se pode explicar, porque o tempo é irreversível e tudo fica mais confuso se for notado que os actantes se misturam em épocas, ontologias e gêneros diferentes. O conceito de modernidade como novidade é amplamente utilizado pelo método oficial no universo da tecnologia da informação. Sempre se propõe essa ruptura deixando o velho, estanque no passado. Dentro da materialidade, a indústria deixa de oferecer compatibilidade, suporte técnico e outras ações necessárias para o (bom) funcionamento do produto, agora ultrapassado pela nova versão, moderna. Essa prática, além de deixar órfãos usuários, produz um viés, para o qual a burla se torna o único método possível.

\section{Simetria}

Segundo Latour (1994) o conceito de simetria explica com os mesmos termos as verdades e os erros, estuda ao mesmo tempo a produção dos humanos e dos não-humanos, ocupa uma posição intermediária entre os terrenos tradicionais e os novos nos assim chamados coletivos (Produções de naturezas-cultura) dos humanosentre-si e das coisas-em-si.

O conceito de simetria pode ser usado como metáfora para entendermos a concomitância dos caminhos oficiais e os em que a tecnologia da informação é burlada. Latour estabelece o princípio generalizado de simetria, segundo o qual os erros e os acertos científicos devem ser simetricamente estudados. Ao tomar a prática científica como campo privilegiado de suas investigações, Latour acompanha como essas práticas são construídas e constituídas. Para isso, ele foca não a ciência feita, pronta e confirmada, mas a ciência em ação, que define no mesmo processo, o seu conteúdo e o contexto social. (Moraes, 2001). Defendo aqui a ideia que o método oficial da tecnologia da informação e a burla desse método são simétricos no sentido de não existirem sem o outro. No instante que é produzida e lançada uma tecnologia oficial (ainda que não seja definitiva) todos os atores burladores se movimentam sobre esse lançamento. Não há a menor distância entre a indústria a prática sociotécnica. Só o tempo separa o lançamento oficial e fechado (em sua caixa preta) e os novos jeitos de se atingir o output do objeto 
lançado. Múltiplas conexões sociotécnicas se constroem inclusive entre esses dois universos. A permeabilidade dos mundos se nota no vazamento de informações técnicas confidenciais, de protótipos "esquecidos" (que, estudados e divulgados aumentam seu espaço na mídia) e na utilização do poder de consumo do universo da burla pelo sistema oficial.

O desenvolvimento tecnológico resulta de um grande número de decisões feitas por numerosos atores heterogêneos. Estes naturalmente incluem os cientistas e engenheiros envolvidos diretamente, mas cada vez mais envolvem a participação dos usuários, dos mundos dos negócios e das finanças e de todos os níveis de governo. Estes parceiros negociam as opções técnicas e, em alguns casos - depois do que pode ser uma longa série de aproximações sucessivas - atingem acordos mutuamente satisfatórios. A diversidade de centros e critérios de decisão implica em algum grau de plasticidade técnica. (Callon, 1995)

Callon também fala sobre redes de concepção-adoção e seu papel na conformação dos artefatos tecnológicos. Acontece a adoção do artefato que é estabilizado como fruto dessa convergência. 0 tamanho da reação e da quantidade de aliados varia de acordo com o tamanho da permeabilidade que a burla produz.

\section{Burlartefato}

O termo pseudolúdico "Burlartefato" reconhece e denomina os produtos da tecnologia da informação em qualquer esfera, que são modificados, alterados, reproduzidos e reinventados pela prática sociotécnica. Sempre existe a possibilidade de se abrir a caixa preta que é comercializada, adequando-a a materialidade do seu uso, dentro das condições em que elas são inseridas.

A produção dos burlartefatos só é possível graças à capacidade de adaptação do objeto passível de burla. Burlar é fazer de outro jeito. É, a partir da função inicial, adaptar as condições ambientais dentro da estrutura e técnica existente. John Law (2004), usa como exemplo para explicar essa conduta a pesquisa feita por Marianne de Laet e Annemarie Mol em um vilarejo de uma província no Zimbabwe. Foram distribuídas pelo governo bombas $d$ 'água aos habitantes que deveriam se organizar para instalar e dar manutenção à bomba. A burla aqui atua como protagonista e único método de prática possível, já que cabia ao coletivo do vilarejo cuidar do dispositivo. A bomba foi sendo adaptada na realidade dos locais que elas foram instaladas. O que as pesquisadoras definiram como a tecnologia fluida. As bombas já não eram as mesmas que saíram da fábrica com seu manual de instrução definidor de procedimentos oficiais. Em função da dificuldade de se substituir peças e usar as ferramentas 
adequadas à manutenção, a prática local era criativa e burlava os métodos definidos e conseguiam manter suas bombas em funcionamento. A teoria de se criar um coletivo para cuidar da bomba imposta como política do governo local não acontecia na prática que se materializava no cuidado de poucos responsáveis pela bomba. Cada vilarejo que recebeu uma bomba para usar e cuidar tinha agora sua própria bomba, adaptada à sua moda, ao fazer resultante do encontro da bomba com os recursos disponíveis. Isso não aconteceria se apenas o método oficial fosse adotado. Decerto, elas estariam jazendo sob a poeira e ferrugem acumulada. Sem a fluidez da tecnologia e a burla do convencional elas simplesmente não funcionariam. A história da bomba d'água do Zimbabwe é o mais belo exemplo da construção de um Burlartefato.

\section{0 burlar}

Por possuir inúmeros sentidos, burlar não pode ter apenas a conotação subversiva inerente ao senso comum da palavra. Burlar pode ser fazer diferente do estabelecido. A burla performa-se em suas relações como agente modificadora de uma realidade até então estabilizada em um processo determinado. É a prática para solução de questões que aparecem em meio à própria experiência cotidiana. Podemos perceber que a técnica da informática burla a dificuldade de controle da informação, tornando automático seu processamento. Um moinho burla o curso do rio, tirando dele a força para suas pás se moverem. Burlar tem como definição em qualquer dicionário um aspecto negativo: despojar, enganar, esbulhar, espoliar, falsificar, fraudar, lesar, trampolinar, trapacear e usurpar. Burlar pode ser também fazer de outro jeito, produzir caminhos não convencionais, alterar o método pré-definido, conceber alternativas em função do possível momentâneo. Apesar de usar como definição-padrão para a burla o sentido de fazer diferente, independente da intenção. Não se deve excluir, por obstante, a burla da definição. Aquela que tem sentido negativo, que sobrepuja e desrespeita o método apenas para obter vantagem material ou financeira. A grande reflexão proposta nesse trabalho é entender a inerência da burla enquanto parte integrante de todos os processos da tecnologia da informação, independente das motivações que a levaram a acontecer. O burlar, enquanto postura de não seguir regras flui através da prática, de um empirismo produzido no lidar diário contra pré-determinações metodológicas que estabelecem regras prontas, fechadas.

A TIC é perpassada multifacetadamente à experiência prática dos usuários que produzem técnicas diferentes que se fazem na interação deles com os dispositivos padronizados. E raros são os protocolos obedecidos à risca. Não que eles tenham o intuito maquiavélico de 
distorcer a práxis oficial, mas simplesmente porque cada experiência cotidiana constrói sua própria particularidade. Não é possível seguir sempre rigorosamente o manual. Peças dadas como defeituosas podem funcionar perfeitamente em outro conjunto, pois quase infinitas variáveis existem. O usuário é sempre um testador, precisa sempre ver se funciona, se atende ao anseio pela funcionalidade. $O$ burlar se torna quase necessário, quando o cotidiano se choca com a expectativa teórica do que foi definido por quem produziu a técnica. Tudo é feito nas cercanias do saber cotidiano. A riqueza de possibilidades e a necessidade de fazer funcionar os dispositivos incitam a burlados caminhos para se chegar à afirmativa: está funcionando!

As regras limitam e restringem a prática. O que o método oficial institui é tomado como verdade como em uma caixa preta (Latour, 2000). Mexer nisso desarruma, burla o instituído, pois esse instituído às vezes não dá conta da prática. Não se trata de dizer que a regra não é importante, mas se não for adequada a novas institucionalizações, a novos princípios essas regras acabam ultrapassadas ou alteradas na sua letra. A burla é quase sempre o caminho para instituir coisas novas que geram pontos de abertura que desarrumam o método oficial. Como gerenciar tantas regras em meio à dinâmica dos movimentos transformadores do cotidiano. As regras são necessárias para se entender os parâmetros que estabelecem o que foi implementado, mas no momento da experimentação dessa prática há o encontro com o instante da experiência cotidiana. As regras assim precisam ser repensadas dentro dessa materialidade através dos elementos que as constituem, tem que de certa forma burlar a regra antiga e estabelecer a nova. Assim, a tecnologia da informação evoluiu ao longo da sua história, nas experiências dos usuários, na adaptação de programas e dispositivos e outras dinâmicas sociotécnicas, dentro de suas necessidades, dentro de sua prática.

A prática do burlar se constrói de maneira natural, pois ela está inscrita na maneira de agir dos atores envolvidos em todo o processo de desenvolvimento da tecnologia da informação. Programas são códigos que podem ser alterados. O comércio torna ilegal algo que é essencialmente parte integrante do processo de produção. Parece que essa proibição só é praticada quando passa a afetar o balanço financeiro das empresas. Assim quando o artefato é produzido como o intuito de obter lucro com sua venda, em seu preço já estão embutidas as "perdas" com as cópias desse artefato.

Questionar a regra instituída é condicioná-la a uma reflexão sobre se ela é a melhor maneira de se alcançar o objetivo proposto e ocorre quando a dinâmica da experiência prática acontece. Não adianta tentar seguir a norma como regra pura. Se o operário só fizer aquilo que atribuíram ele a fazer a coisa pode não funcionar. É preciso ver e 
estar atento aos elementos que compõem todo o coletivo. A prática produz transformações nas coordenadas recebidas em uma dinâmica que circunda. A situação, os recursos disponíveis não são sempre os mesmos do que espera a teoria. Colocar algo para funcionar implica em negociações. Burlar é muito mais do que inviabilidade de seguir algo a risca, pois na materialidade ocorrem mediações, imprevistos que vão exigir que essas negociações aconteçam. Demandas permitirão que soluções ocorram para situações que vão envolver a entrada de novos elementos que desarrumam a suposta pureza original da orientação fechada do método oficial.

O pensamento moderno tende a purificar, a seguir à risca o manual, a pré-estabelecer direção e sentido nas coisas. Toda a estabilização é temporária. Como se pode ter clareza sobre o que se pode ou não fazer? Como ignorar quando uma nova maneira de se fazer algo já estabilizado aparece e permite fazer algo de outra forma, mais fácil ou mais barata? O convite é para se repensar o ato de burlar, não como mais algo a ser combatido. A ideia de pureza precisa ser revista, a burla tem a faceta de questionamento de pureza.

\section{A burla e sua motivação}

O que se define como método de uso de um dispositivo, descrito em seus manuais não produz uma regra de obediência à risca do que está escrito lá. A burla faz circular novos usos para os dispositivos e produz novas conexões possíveis. A pílula anticoncepcional modificou a sexualidade feminina. O Viagra, o transistor, o Prozac, o chip, a eletricidade, a internet. Cada novo dispositivo provoca novos arranjos e desarranjam outros, mudam aspectos psicológicos e comportamentos do individuo perante esses novos arranjos. Novas negociações ocorrem. Os princípios da organização da internet e das novas tecnologias são a personificação de praticamente todas as grandes instalações ideológicas contemporâneas: o pluralismo, a descentralização, a fragmentação, a intertextualidade, sempre sendo talhadas numa prática contínua e que se desdobra.

A narrativa de quem pratica a burla ideológica quando indagado sobre suas motivações possui sempre um mesmo padrão de resposta: 0 prazer de vencer o desafio de quebrar o método. 0 aprisionamento técnico praticado pelos criadores do método convencional também aparecem como motivação.

O burlar surge da prática da informática que tem sempre o burlar inserido como recurso disponível na construção dos mundos possíveis porque essa premissa está embrenhada na performance da informática. Lidar com tecnologia da informação implica na possibilidade de burlar e burlar emerge da prática da tecnologia da informação. Praticar informática implica em praticar o burlar, em 
níveis distintos. Os atores que burlam explicitamente são actantes na rede em que eles estão inseridos. Não são algo de fora que faz contato momentaneamente inserido. Eles são parte integrante do processo inteiro, desde sempre.

A necessidade de improviso, frente a situações de recursos escassos, a adaptação que intenciona promover o funcionamento mais simples ou em uma melhor conformação dentro da prática cotidiana da utilização de um determinado dispositivo gera a clara percepção que as coisas são, no sentido ontológico, sempre em relação ao contexto que elas estão inseridas.

Há na cultura brasileira, a ideia de um coletivo de população tomado como inventivo, criativo, produtor de improvisos funcionais dos mais variados tipos. O tão falado "jeitinho Brasileiro" poderia ser visto como um movimento de inventividade se fosse retirado desse conceito a alcunha da lei de Gerson24. Tal qual a maneira inventiva dos povos que habitam os vilarejos no Zimbabwe, a frase "dar um jeito" é sinonímia de uma inventividade produzida na prática do uso e na interação com dispositivos dentro do contexto da sua aplicação. A dificuldade e a carência de recursos misturada às características culturais dos brasileiros produz uma criatividade incrível, para atingir objetivos burlam-se os métodos tradicionais e se produz o resultado final de forma improvisada, porém funcional.

Burlar produz movimento nos mecanismos oficiais, porém sempre quando atinge um nível critico de incomodo. Elas atravessam o sistema instituído. A burla inventiva altera funções pré-determinadas de alguns objetos, que podem ser usados com outra função diferente da qual ele foi desenvolvido ou designado para tal.

Compreendemos que a única maneira de uma razoável de realista de uma mente discorrer com veracidade sobre o mundo é reconectarmos por meio do maior numero possível de relações e vasos, à rica vascularização que faz a ciência fluir. (Latour, 2001)

O principal argumento aqui é a percepção de que, por ser um meio de computar a informação, a informática sempre buscou produzir maneiras mais fáceis de se obter o resultado esperado. Sempre há mais de uma maneira de realizá-lo, pois sistemas são o jeito processual de se chegar a um determinado resultado a partir de uma entrada da informação. Como ele é o caminho para se chegar de um ponto ao outro, sempre se pode percorrer diferentes caminhos para se chegar a um mesmo lugar. Como no mundo da tecnologia da informação sempre se deseja a melhor performance (rapidez, custo, facilidade e resultado), está assim, intrínseco à prática, a procura de uma melhor maneira de se obter o resultado esperado, ainda que seja burlando o método oficial.

A burla possui caráter às vezes generalista, porém recebe influência de particularidades regionais. Dependendo de onde ela se aplica às vezes é vista como originalidade ou adaptabilidade em outras pode 
ser criminalizada. Devemos sempre adotar um olhar prático para entender as particularidades de cada concatenação onde a burla aparece.

As práticas de burla são tão antigas quanto às práticas convencionais. Elas sempre coexistiram e são inseparáveis. A burla assim se perfaz um tanto recalcitrante em relação às normas estabelecidas como verdades teóricas, que precisam ser repensadas sem o peso do julgamento sobre certo ou errado. Burlar está presente como um gel que permeia o método oficial e que dá liga ao funcionamento de todo o engendramento sociotécnico. Assim como ciência e política não são separadas em sua materialidade, o desenvolvimento tecnológico da informação e o uso da tecnologia como agente modificador de situações cotidianas também não devem ser entendidas de forma estanque.

Normas são importantes, para segurança, para o controle e o bom funcionamento de sistemas de todo o tipo. A burla não intenciona o simples desarrumar. Podemos citar o exemplo de um navio de alta tecnologia e complexidade, de padrão rigoroso, de normas préestabelecidas em manuais enormes, tudo padronizado e parametrizado. Se algo sai do controle é porque o protocolo ali escrito não foi obedecido. O burlar, nesse sentido, não é um projeto que visa desestabilizar manuais e comandantes, ele está mais para um índio e sua jangada que chega aos mesmos resultados enquanto qualidade de navegação, é um ótimo navegador que se utiliza de outra dinâmica, mexe com experiência com as variáveis ambientais como vento, temperatura, a operação no mar, o movimento das ondas. É outra dinâmica nãotão presa aos manuais, questionadora que se recolhe quando não é a melhor opção, mas que não deixa de apontar que sempre se pode pensar fora da caixa, achar soluções para problemas de forma criativa, inovadora ou apenas utilizando os recursos disponíveis em uma determinada circunstância.

\section{Referências}

Callon, M. (1995). Technological Conception and Adoption Networks: Lessons for the CTA Practitioner. Managing Technology in Society - The approach of Constructive Technology Assessment. Printer Publishers. Londres.

Freire, L. (2006). Seguindo Bruno Latour: notas para uma antropologia simétrica. Revista Comum, 11(26), 51.

Harman, G. (2009). Prince of Networks. Bruno Latour and Metaphysics. Recuperado em 11 de março, 2011, de: http://www. re-press.org/book-

files/OA_Version_780980544060_Prince_of_Networks.Pdf

Latour, B. (19994). Jamais fomos modernos: ensaio de antropologia 
simétrica. Editora 34. Rio de J aneiro.

Latour, B. (2000). Ciência em Ação: como seguir cientistas e engenheiros sociedade afora. Unesp. São Paulo.

Latour, B. (2001). A esperança de Pandora: ensaios sobre a realidade dos estudos científicos. EDUSC. Bauru/SP

Latour, B. (2004). Como terminar uma tese de sociologia: pequeno diálogo entre um aluno e seu professor (um tanto socrático) Recuperado em 11 de março, 2011, de http://www.brunolatour. fr/sites/default / files/downloads/90-DIALOGUE-POR.pdf

Latour, B. (2006) Changer de société. Refaire de la sociologie. Éditions de la Découverte. Paris

Law, J., \& Urry, J. (2004). Enacting the social. Economy and Society, Lancaster University, Reino Unido.

Moraes, M. O. (2001). A psicologia, uma ciência? Revista Paradoxa, IV (9), 55-64, 2001. Rio de Janeiro.

Tsallis, A. (2009). Palhaços: uma possível reflexão para a Gestaltterapia. Revista Estudos e Pesquisa em Psicologia, 9(1). Rio de Janeiro.

Wilkinson, J. (2004). Redes, convenções e economia política: de atrito à convivência. Paper apresentado no XXVIII Encontro Anual da ANPOCS - Associação Nacional de Pós-Graduação e Pesquisa em Ciências Sociais no seminário temático "Análise sociológica dos fenômenos econômicos". Rio de Janeiro.

\section{Endereço para correspondência \\ Lauro Rodriguez de Pontes}

Universidade do Estado do Rio de Janeiro

Programa de Pós-Graduação em Psicologia Social

Rua São Francisco Xavier, 524, 10 o andar, sala 10.009, bloco F, Maracanã, CEP 20550-013, Rio de Janeiro - RJ, Brasil

Endereço eletrônico: lauro@globo.com

Recebido em: 12/05/2014

Reformulado em: 28/10/2014

Aceito em: 05/11/2014

\section{Notas}

* Doutorando no Programa de Pós-Graduação em Psicologia Social da Universidade do Estado do Rio de Janeiro. Psicólogo, mestre em psicologia social pela Universidade do Estado do Rio de Janeiro 